\title{
Factors associated with non-compliance with breastfeeding recommendation: a retrospective survey in hepatitis B virus- infected mothers who had taken Nucleos(t)ide analogs during pregnancy
}

Er-Mei Li ${ }^{1+}$, Li-Xin Xiao ${ }^{1+}$, Zhen Xu' ${ }^{1}$ Zhi-Shuo Mo ${ }^{1}$, Jia-Qian Li ${ }^{2}$ Yong-Yu Mei ${ }^{{ }^{*}}$ and Chao-Shuang Lin ${ }^{1 *}$

\begin{abstract}
Background: We encourage Hepatitis B virus-infected mothers to breastfeed postpartum, even when continuing pregnancy category B nucleos(t)ide analogs (NAs) treatment. However, a large proportion of the Hepatitis B virusinfected mothers were noncompliant with this breastfeeding recommendation. This study aimed to investigate the factors associated with noncompliance with breastfeeding recommendation in Hepatitis B virus-infected mothers who had received NAs treatment during pregnancy.

Methods: A total of 155 mothers with chronic hepatitis B receiving NAs treatment for preventing mother-to-child transmission during the late gestation period were included and divided into exclusive breastfeeding $(n=63)$, mixed feeding ( $n=34)$, and artificial feeding $(n=58)$ groups according to the postpartum feeding methods. Independent variables associated with feeding methods were analyzed using logistic regression analysis.

Results: Compared to the breastfeeding and mixed feeding groups, the artificial feeding group had significantly more multiparity, later postpartum timing of stopping NAs treatment, and a lower proportion of having knowledge of NAs medications (all $\mathrm{P}<0.05$ ). In addition, multivariable logistic regression analysis confirmed that multiparity, later postpartum timing of stopping NAs treatment, and lacking knowledge of medication were independent factors associated with noncompliance with breastfeeding recommendation.
\end{abstract}

Conclusions: Hepatitis B virus-infected mothers who stopped NAs treatment at late postpartum period or had less knowledge of medication were more likely to be noncompliant with breastfeeding recommendation. Strengthening health education for participants taking NAs may be an important method to improve compliance with breastfeeding recommendation.

Keywords: Chronic hepatitis B, nucleos(t)ide analogs, breastfeeding, patient's compliance

\footnotetext{
*Correspondence: 13729842169@163.com; Ichaosh@mail.sysu.edu.cn

${ }^{\dagger}$ Er-Mei Li and Li-Xin Xiao contributed equally to this work and share first authorship.

'Department of Infectious Diseases, the Third Affiliated Hospital of Sun

Yat-Sen University, 600 Tianhe Road, Guangdong Province 510630 Guangzhou, China

Full list of author information is available at the end of the article
}

(c) The Author(s). 2021 Open Access This article is licensed under a Creative Commons Attribution 4.0 International License, which permits use, sharing, adaptation, distribution and reproduction in any medium or format, as long as you give appropriate credit to the original author(s) and the source, provide a link to the Creative Commons licence, and indicate if changes were made. The images or other third party material in this article are included in the article's Creative Commons licence, unless indicated otherwise in a credit line to the material. If material is not included in the article's Creative Commons licence and your intended use is not permitted by statutory regulation or exceeds the permitted use, you will need to obtain permission directly from the copyright holder. To view a copy of this licence, visit http://creativecommons.org/licenses/by/4.0/. The Creative Commons Public Domain Dedication waiver (http://creativecommons.org/publicdomain/zero/1.0/) applies to the data made available in this article, unless otherwise stated in a credit line to the data. 


\section{Background}

Hepatitis B virus (HBV) infects more than 2 billion people worldwide [1]. According to the World Health Organization (WHO), 257 million people were estimated to be chronically infected with HBV in 2015 worldwide [2], including 65 million women of childbearing age [3]. Mother-to-child transmission (MTCT) is the major route of hepatitis B virus spread, accounting for nearly half of global chronic infections [4]. The active-passive immunization (hepatitis B vaccines plus hepatitis B immunoglobulin [HBIG]) can effectively prevent nearly $90 \%$ of the MTCT of HBV [5]. However, a small portion of newborns still encounters the failure of active-passive immunoprophylaxis in preventing MTCT [6].

Clinical studies in recent years have confirmed that nucleos(t)ide analogs (NAs) treatment, such as tenofovir disoproxil fumarate (TDF) and telbivudine (LDT), in the second and third trimesters of pregnancy can effectively reduce the MTCT of HBV [7-10]. As a result, the guidelines by several liver disease associations, including the Asian Pacific Association for the Study of the Liver (APASL) [11], the European Association for the Study of the Liver (EASL) [12], the National Institute for Health and Care Excellence (NICE) [13] and the American Association for the Study of Liver Diseases (AASLD) [14] all recommend high viral load chronic hepatitis $B(\mathrm{CHB})$ pregnant women at the immune tolerance period to receive pregnancy category B NAs (such as TDF and LDT [15]) during the second and third trimesters to reduce the MTCT rate.

Breastfeeding has many benefits for the mothers (such as postpartum weight management and reducing the risk of ovarian and breast cancer and type 2 diabetes) and infants (such as reducing the risk of respiratory, gastrointestinal, and ear infections in infancy) [16]. Currently, however, there is no consensus on whether HBVinfected mothers receiving pregnancy category B NAs treatment should breastfeed or not. In the WHO guidelines [17] and Asian-Pacific clinical practice guidelines [11], no clear instructions were given about breastfeeding by HBV-infected mothers with TDF treatment. In both 2017 EASL [12] and 2018 AASLD guidelines [14], breastfeeding is not contraindicated in HBsAg-positive women on TDF-based treatment or prophylaxis. The 2015 Chinese guideline by the Hepatology Branch of Chinese Medical Association [18] did not recommend breastfeeding for mothers who need to continue pregnancy category B medications postpartum. In the 2019 Chinese guidelines [19], breastfeeding is no longer prohibited for HBV-infected mothers receiving NAs for preventing MTCT during the gestation period, but breastfeeding is still not clearly recommended.

It has been reported that breastfed infants have extremely lower TDF exposure than those exposed in the fetuses or children receiving tenofovir treatment [2022]. TDF and LDT belong to pregnancy Category B medications, and TDF has low potential toxicity in breastmilk. Therefore, we believe that breastfeeding should not be contraindicated in HBV-infected mothers on NAs treatment. In clinical practice, we recommend HBV-infected mothers to breastfeed postpartum, even when continuing pregnancy category B NAs treatment. We had previously conducted a prospective study on the safety of NA withdrawal in pregnant women with chronic hepatitis B in the immune tolerance period [23]. In the follow-up during the medication period, we conducted health education for these patients to advocate postpartum breastfeeding. However, it was found that a significant proportion of the $\mathrm{HBV}$-infected mothers did not follow the breastfeeding recommendations and instead adopted artificial feeding. Therefore, the purpose of this study was to investigate the factors associated with noncompliance with breastfeeding recommendation in $\mathrm{HBV}$-infected mothers who had received NAs treatment during pregnancy for preventing MTCT.

\section{Methods \\ Study design and participants}

This was a retrospective survey from January 2017 to August 2019, in the Department of Infectious Disease of the Third Affiliated Hospital of Sun Yat-sen University, Guangzhou, China.

A total of 85 participants were retrospectively included from our previous study [1]. To expand the sample size of the study, another $78 \mathrm{HBV}$-infected women who met the inclusion criteria and had completed LDT/TDF treatment were included. A total of 163 participants were screened, and 8 of them withdrew their informed consent. Thus, $155 \mathrm{CHB}$ participants with high viremia and in the immune-tolerant phase receiving NAs treatment for preventing MTCT during the gestation period were included. The flowchart of patient selection was shown in Fig. 1.

After the participants decided to receive medical treatment and signed the informed consent, health education was given during pregnancy, including the safety of LDT/TDF treatment and the safety of breastfeeding during the treatment. We ensured that the participants had sufficient knowledge about the following issues: 1). The safety of using this type of drug during pregnancy, 2). Whether it is necessary to continue antiviral treatment to block the mother-to-child transmission of HBV after delivery; 3) Whether it is possible to breastfeed when continuing antiviral therapy or stopping the drug during lactation. All participants were followed up for 12 months after delivery. The patients were also given health education on the risks and benefits of stopping the medication therapy immediately after delivery or at 


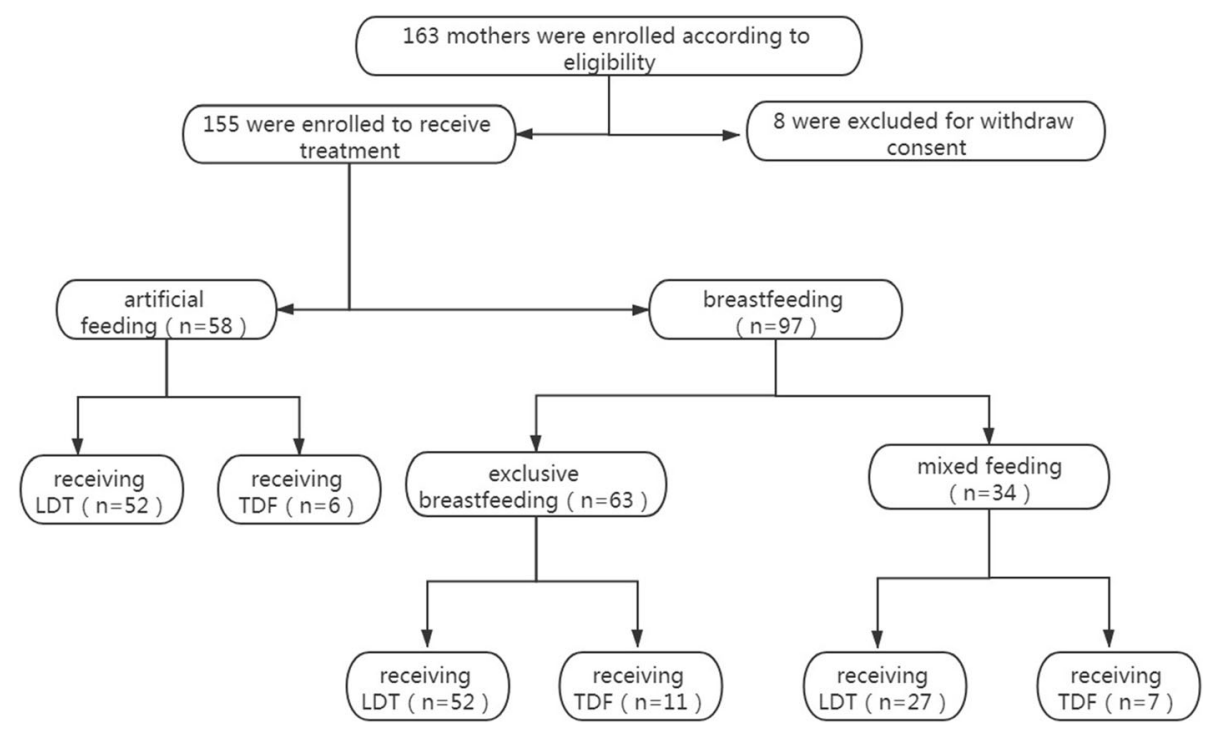

Fig. 1 The flow chart of the study. LdT, telbivudine; TDF, tenofovir disoproxil fumarate

6 weeks postpartum or more. After which, the participants would decide the timing of cessation of medication treatment by themselves.

The inclusion criteria were: (1) age between 18 and 45 years; (2) detectable HBsAg at the screening visit and at least 6 months prior; (3) positivity for serum HBeAg, HBV DNA level above $10^{6} \mathrm{IU} / \mathrm{ml}$, and ALT level below the upper limit of normal (ULN; 40U/L). The exclusion criteria were: (1) coinfection with hepatitis $\mathrm{A}, \mathrm{C}, \mathrm{D}$, or $\mathrm{E}$ virus or human immunodeficiency virus; (2) previous AVT for HBV infection (except for antivirals administered to prevent MTCT during a previous pregnancy and discontinued more than 6 months before the current pregnancy); (3) concurrent treatment with cytotoxic drugs, immune modulators, glucocorticoids or nephrotoxic drugs; (4) clinical signs of threatened miscarriage in early pregnancy; (5) evidence of hepatocellular carcinoma or cirrhosis; (6) evidence of fetal deformity by 3dimensional ultrasound examination; (7) history of congenital malformation or congenital genetic disease in a previous pregnancy; (8) HBV infection of the husband (If the baby born to HBV-infected mother was still infected HBV even after receiving active-passive immunoprophylaxis, the possibility of father to child transmission can be ruled out).

This study was approved by the institutional review board of the Third Affiliated Hospital of Sun Yat-Sen University, Guangzhou (approval no. [2015]2-102). Written informed consent was obtained from each participant.

\section{Demographic and clinical characteristics}

Participants' demographic and clinical characteristics were collected from the medical records. Demographic and clinical characteristics were collected, mainly including age, education level, work status, fetal gender parity, delivery method, knowledge of medication (LDT/ TDF), gestational age at the start of anti-viral therapy, postpartum timing of stopping NAs treatment, postpartum liver function and viral load, vaccination status, breastfeeding time, and whether breastfeeding with wounds. These data were categorized into categorical variables and continuous variables for statistical analysis.

\section{Data collection}

All patients were followed up by telephone, and the information of all patients was recorded in the medical record. Artificial feeding was defined as using cow's milk, goat's milk, or other suitable milk substitutes including infant formula to feed the baby. A self-administered questionnaire (Supplementary material) was designed to collect the data including education level, working status, parity, delivery methods, the gestational age at the start of oral antiviral drugs, postpartum timing of stopping NAs treatment, postpartum liver function, postpartum viral load, infant gender, vaccination status, successful hepatitis b vaccination, breastfeeding time, breastfeeding with wounds, the decision of feeding method, child with unusually healthy issue, child with unusual height or weight, education on knowledge of medication (LDT/TDF) during prenatal care checkups.

Patients meeting the inclusion criteria would sign the informed consent form when taking NAs for preventing MTCT in the prenatal period, and they were formally included in the group during the return visit after delivery. Meanwhile, they were given questionnaires and telephone communication forms for long-term post-natal follow-up. 
The patient's knowledge of medication (LDT/TDF) was evaluated by a specialist doctor using a self-designed scale that consisted of several questions about motherto-child transmission of LDT / TDF drugs.

\section{Statistical analysis}

Continuous data were indicated with mean \pm standard deviation (SD). For the comparisons between the two groups, the independent t-test or Mann-Whitney $U$ test (if normality was not assumed) was used. Categorical data were indicated with number and percentage (\%), and the distribution would be tested with the Chi-square test or Fisher's exact test (if any expected value $<=5$ was observed). One-way ANOVA was used for the means among groups (over 2 groups) and Fisher's LSD test was used as post-hoc comparisons. Kruskal-Wallis would be used as a replacement if normality was not assumed. To investigate the associations between independent variables and feeding methods, the univariate and multivariable logistic regression models were used. The variables which reached $\mathrm{P}<0.10$ in the comparisons of mean differences were analyzed using logistic regression models. The significant variables $(\mathrm{P}<0.05)$ in the multivariable model were recognized as factors associated with feeding methods. ROC analysis was used to investigate the diagnostic efficacy of continuous variables to dichotomous outcomes. A $\mathrm{P}<0.05$ was recognized as reaching the significance of each test, two-tailed. All analyses were performed using IBM SPSS Version 25 (SPSS Statistics V25, IBM Corporation, Somers, New York).

\section{Results}

\section{Participant's demographic and clinical characteristics}

A total of $155 \mathrm{CHB}$ mothers (mean age $=29.50 \pm 3.55$ years) receiving NAs treatment for preventing MTCT during the gestation period were included. Participant's demographic and clinical characteristics were summarized in Table 1. NAs antiviral treatment included LDT $(\mathrm{n}=131,84.52 \%)$ and TDF $(\mathrm{n}=24,15.48 \%)$. The mean gestational age was $39.92 \pm 2.41$ weeks. The delivery methods included vaginal $(\mathrm{n}=114,73.55 \%)$ and cesarean section deliveries $(\mathrm{n}=41,26.45 \%)$.

According to the postpartum feeding methods, the participants were divided into three groups: exclusive breastfeeding ( $\mathrm{n}=63,40.65 \%)$, mixed feeding $(\mathrm{n}=34$, $21.94 \%)$, and artificial feeding $(\mathrm{n}=58,37.41 \%)$ groups. The majority of participants $(\mathrm{n}=111,71.61 \%)$ had their first parity. It was found that participants with multiparity were more likely to use artificial feeding $(P=0.003)$. The later the postpartum timing of stopping NAs treatment, the greater the possibility of using artificial feeding $(P=0.022)$. Participants who had more knowledge of medication (LDT/TDF) were more likely to have breastfeeding $(\mathrm{P}<0.001)$. The exclusive breastfeeding group had significantly longer breastfeeding months than the mixed feeding group $(\mathrm{P}<0.001)$.

\begin{tabular}{llllll}
\hline Parameters & $\mathbf{N}$ & $\begin{array}{l}\text { Exclusive } \\
\text { breastfeeding }\end{array}$ & $\begin{array}{l}\text { Mixed } \\
\text { feeding }\end{array}$ & $\begin{array}{l}\text { Artificial } \\
\text { feeding }\end{array}$ & $\begin{array}{l}\mathbf{P} \\
\text { value }\end{array}$ \\
\hline Parity & & & & $<$ \\
Primiparous & 108 & $53(49.1 \%)$ & $23(21.3 \%)$ & $32(29.6 \%)$ & 0.001 \\
Multiparous & 42 & $8(19.0 \%)$ & $8(19.0 \%)$ & $26(61.9 \%)$ & \\
\hline
\end{tabular}

${ }^{a}$ Three mothers did not provide their parity, of which two were exclusively breastfeeding and one was mixed feeding; one of primiparous did not provide the feeding method, and one of the multiparous mother did not provide the feeding method

\section{Participant's clinical characteristics between groups with or without breastfeeding}

Participants were further dichotomously divided into groups with or without breastfeeding (mixed feeding includes breastfeeding). As shown in Table 2, the significances were similar to Table 1 . The artificial feeding group had significantly multiparity, later postpartum timing of stopping NAs treatment, and a lower level of knowledge of medication (all $\mathrm{P}<0.05$ ).

\section{Independent variables associated with feeding methods}

To further investigate the independent variables associated with feeding methods (with or without breastfeeding), logistic regression analysis was performed. The variables reaching $\mathrm{P}<0.10$ in Table 2 were included in the univariate and multivariable logistic regression models, such as educational level, parity, postpartum timing of stopping NAs treatment, infant birth bodyweight, and knowledge of medication.

As shown in Table 3, the independent factors associated with feeding methods were parity, postpartum timing of stopping NAs treatment, and knowledge of medication (all $\mathrm{P}<0.01$ ). These results suggested that participants with multiparity, later postpartum timing of stopping NAs treatment, and less knowledge of medication were more likely to use artificial feeding.

\section{Discussion}

The subject of breastfeeding among HBV-positive mothers has attracted more and more attention. Previous studies demonstrate that breastfeeding by HBVinfected mothers is safe and does not increase the risk of MTCT if the newborns have received active-passive immunoprophylaxis $[24,25]$, including $\mathrm{HBeAg}^{+} \mathrm{CHB}$ mothers [26]. Although a previous study has shown that HBsAg, HBeAg, and HBV DNA may be presented in breastmilk [27] but generally cannot enter the infant 
Table 1 Clinical characteristics among different feeding methods

\begin{tabular}{|c|c|c|c|c|c|c|}
\hline Parameters & $\mathbf{N}$ & $\begin{array}{l}\text { Exclusive breastfeeding } \\
(n=63)\end{array}$ & $\begin{array}{l}\text { Mixed feeding }(n= \\
\text { 34) }\end{array}$ & $\begin{array}{l}\text { Artificial feeding }(n= \\
58)\end{array}$ & $\begin{array}{l}\text { All }(n= \\
155)\end{array}$ & $\mathbf{P}$ \\
\hline Age, year & 155 & $29.08 \pm 3.30$ & $27.88 \pm 2.96$ & $29.50 \pm 3.55$ & $\begin{array}{l}28.97 \pm \\
3.36\end{array}$ & 0.079 \\
\hline Educational level & & & & & & 0.233 \\
\hline Junior and senior high & 31 & 8 (25.81\%) & 6 (19.35\%) & $17(54.84 \%)$ & - & \\
\hline Undergraduate & 108 & $47(43.52 \%)$ & $25(23.15 \%)$ & $36(33.33 \%)$ & - & \\
\hline Graduate and above & 16 & $8(50.00 \%)$ & $3(18.75 \%)$ & $5(31.25 \%)$ & - & \\
\hline Work status & & & & & & 0.933 \\
\hline Unemployed & 42 & 17 (40.48\%) & $9(21.43 \%)$ & 16 (38.10\%) & - & \\
\hline Part-time or freelance & 14 & 7 (50.00\%) & $2(14.29 \%)$ & $5(35.71 \%)$ & - & \\
\hline Full-time & 99 & 39 (39.39\%) & $23(23.23 \%)$ & 37 (37.37\%) & - & \\
\hline \multicolumn{7}{|l|}{ aparity } \\
\hline Primiparous & 108 & $53(49.1 \%)$ & $23(21.3 \%)$ & $32(29.6 \%)$ & & $<0.001$ \\
\hline Multiparous & 42 & $8(19.0 \%)$ & $8(19.0 \%)$ & $26(61.9 \%)$ & & \\
\hline Delivery method & & & & & & 0.366 \\
\hline Vaginal & 114 & 48 (42.11\%) & $27(23.68 \%)$ & 39 (34.21 \%) & - & \\
\hline Cesarean section & 41 & 15 (36.59\%) & 7 (17.07\%) & 19 (46.34\%) & - & \\
\hline Medication & & & & & & 0.361 \\
\hline LDT & 131 & $52(39.69 \%)$ & 27 (20.61 \%) & 52 (39.69\%) & - & \\
\hline TDF & 24 & $11(45.83 \%)$ & 7 (29.17\%) & $6(25.00 \%)$ & - & \\
\hline $\begin{array}{l}\text { Gestational age at start of anti-viral } \\
\text { therapy }\end{array}$ & 155 & $25.19 \pm 4.17$ & $24.18 \pm 4.07$ & $24.67 \pm 2.96$ & $\begin{array}{l}24.77 \pm \\
3.73\end{array}$ & 0.430 \\
\hline $\begin{array}{l}\text { Postpartum timing of stopping NAs } \\
\text { treatment }\end{array}$ & & & & & & 0.022 \\
\hline Delivery day & 110 & $50(45.45 \%)$ & $28(25.45 \%)$ & $32(29.09 \%)$ & - & \\
\hline 1 month & 3 & $1(33.33 \%)$ & $2(66.67 \%)$ & $0(0.00 \%)$ & - & \\
\hline 1.5 months & 18 & $6(33.33 \%)$ & $2(11.11 \%)$ & $10(55.56 \%)$ & - & \\
\hline 2 months & 1 & 1 (100.00 \%) & $0(0.00 \%)$ & $0(0.00 \%)$ & - & \\
\hline 3 months & 1 & 1 (100.00 \%) & $0(0.00 \%)$ & $0(0.00 \%)$ & - & \\
\hline 6 months & 1 & $0(0.00 \%)$ & $0(0.00 \%)$ & $1(100.00 \%)$ & - & \\
\hline 9 months & 1 & $0(0.00 \%)$ & $0(0.00 \%)$ & $1(100.00 \%)$ & - & \\
\hline Never & 20 & $4(20.00 \%)$ & $2(10.00 \%)$ & 14 (70.00 \%) & - & \\
\hline Postpartum liver function & & & & & & 0.158 \\
\hline Normal & 94 & 39 (41.49\%) & $22(23.40 \%)$ & $33(35.11 \%)$ & - & \\
\hline Index rising & 23 & $9(39.13 \%)$ & $2(8.70 \%)$ & $12(52.17 \%)$ & - & \\
\hline Postpartum viral load & & & & & & 0.028 \\
\hline Normal & 54 & $18(33.33 \%)$ & $19(35.19 \%)$ & $17(31.48 \%)$ & - & \\
\hline Abnormal & 79 & 35 (44.30 \%) & $12(15.19 \%)$ & $32(40.51 \%)$ & - & \\
\hline Infant gender & & & & & & 0.524 \\
\hline Male & 78 & 34 (43.59\%) & $18(23.08 \%)$ & $26(33.33 \%)$ & - & \\
\hline Female & 76 & $28(36.84 \%)$ & $16(21.05 \%)$ & $32(42.11 \%)$ & - & \\
\hline Vaccination on time & & & & & & 0.405 \\
\hline No & 1 & 1 (100.00 \%) & $0(0.00 \%)$ & $0(0.00 \%)$ & - & \\
\hline Yes & 154 & $62(40.26 \%)$ & $34(22.08 \%)$ & $58(37.66 \%)$ & - & \\
\hline Successful hepatitis B vaccination & & & & & & 0.054 \\
\hline
\end{tabular}


Table 1 Clinical characteristics among different feeding methods (Continued)

\begin{tabular}{|c|c|c|c|c|c|c|}
\hline Parameters & $\mathbf{N}$ & $\begin{array}{l}\text { Exclusive breastfeeding } \\
(n=63)\end{array}$ & $\begin{array}{l}\text { Mixed feeding }(n= \\
34)\end{array}$ & $\begin{array}{l}\text { Artificial feeding }(n= \\
58)\end{array}$ & $\begin{array}{l}\text { All }(n= \\
155)\end{array}$ & $\mathbf{P}$ \\
\hline No & 5 & $0(0.00 \%)$ & $1(20.00 \%)$ & $4(80.00 \%)$ & - & \\
\hline Yes & 142 & $59(41.55 \%)$ & $30(21.13 \%)$ & $53(37.32 \%)$ & - & \\
\hline Breastfeeding months & - & $9.16 \pm 4.38$ & $5.56 \pm 3.64$ & - & $7.92 \pm 4.47$ & $<0.001$ \\
\hline Breastfeeding with wounds ${ }^{*}$ & & & & & & 0.314 \\
\hline No & 57 & $38(66.67 \%)$ & $19(33.33 \%)$ & $0(0.00 \%)$ & - & \\
\hline Yes & 32 & 19 (59.38 \%) & $12(37.50 \%)$ & $1(3.13 \%)$ & - & \\
\hline Decision of feeding method & & & & & & 0.319 \\
\hline Both parents & 85 & $36(42.35 \%)$ & $20(23.53 \%)$ & $29(34.12 \%)$ & - & \\
\hline Physician & 39 & $19(48.72 \%)$ & $6(15.38 \%)$ & $14(35.90 \%)$ & - & \\
\hline Mother alone & 31 & $8(25.81 \%)$ & $8(25.81 \%)$ & $15(48.39 \%)$ & - & \\
\hline Infant birth body weight, $\mathrm{kg}$ & 155 & $4.22 \pm 1.65$ & $4.02 \pm 1.43$ & $3.71 \pm 1.38$ & $3.99 \pm 1.51$ & 0.179 \\
\hline Infant birth body length, $\mathrm{cm}$ & 155 & $48.94 \pm 3.42$ & $49.82 \pm 2.39$ & $49.40 \pm 2.09$ & $\begin{array}{l}49.31 \pm \\
2.76\end{array}$ & 0.315 \\
\hline Child with unusually healthy issue & & & & & & 0.791 \\
\hline No & 143 & $59(41.26 \%)$ & $31(21.68 \%)$ & $53(37.06 \%)$ & - & \\
\hline Yes & 4 & 1 (25.00\%) & $1(25.00 \%)$ & $2(50.00 \%)$ & - & \\
\hline Knowledge of medication (LDT/TDF) & & & & & & $<0.001$ \\
\hline No & 32 & $4(12.50 \%)$ & $6(18.75 \%)$ & $22(68.75 \%)$ & - & \\
\hline Yes & 120 & $58(48.33 \%)$ & $28(23.33 \%)$ & $34(28.33 \%)$ & - & \\
\hline Child with unusual height or weight & & & & & & 0.382 \\
\hline No & 149 & $61(40.94 \%)$ & $33(22.15 \%)$ & 55 (36.91 \%) & - & \\
\hline Yes & 3 & 1 (33.33\%) & $0(0.00 \%)$ & $2(66.67 \%)$ & - & \\
\hline
\end{tabular}

${ }^{\text {a }}$ Three mothers did not provide their parity, of which two were exclusively breastfeeding and one was mixed feeding; one of primiparous did not provide the feeding method, and one of the multiparous mother did not provide the feeding method

"Breastfeeding with wounds" was defined as follows: 1) The mother's nipples were chapped or damaged, causing the baby to directly contact with the mother's blood during breastfeeding; or 2) The baby's lips and mouth may be damaged which can directly contact with breast milk

blood through the internal barrier of the intestinal mucosa. Only when mucosal permeability is increased due to complications or injuries, the virus can enter the infant's blood [28]. Therefore, guidelines have suggested that breastfeeding should be encouraged for infants undergoing the standard passive-active immunoprophylaxis $[5,29,30]$. However, there is no consensus on whether HBV-infected mothers receiving pregnancy category B NAs treatment should breastfeed. The 2015 Chinese guideline [18] did not recommend breastfeeding for mothers who need to continue pregnancy category B medications postpartum.

Although the label of antiviral drugs does not recommend breastfeeding while taking these drugs, clinical studies support the safety of these drugs during breastfeeding $[31,32]$. The TDF and LDT belong to pregnancy Category B medications, and TDF has low potential toxicity in breastmilk [20-22]. In addition, both 2017 EASL [12] and 2018 AASLD guidelines [14] suggest that breastfeeding is not contraindicated in HBsAg-positive women receiving TDF-based treatment. Therefore, we encourage HBV-infected mothers to breastfeed postpartum, even when continuing pregnancy category B NAs treatment. TDF and LDT can quickly and effectively reduce the HBV DNA viral load of HBV-infected mothers. In addition, these nephrotoxic drugs are also safe and do not increase the risk of fetal birth defects or other serious diseases [33, 34]. Compared with the general population, the current study observed a similar rate of birth defects among infants with exposure to LDT/ TDF $[9,34]$. However, a large proportion of the HBVinfected mothers did not follow the breastfeeding recommendation. In the current study, of the 155 pregnant $\mathrm{CHB}$ women receiving NAs treatment during the gestation period, only $40.65 \%$ of cases underwent exclusive breastfeeding.

In this study, we investigated the factors associated with noncompliance with breastfeeding recommendation in HBV-infected mothers who had received NAs treatment during pregnancy. Our results showed that the artificial feeding group had significantly multiparity than the breastfeeding and mixed feeding groups and multivariable logistic regression analysis showed that multiparity was the independent factor associated with 
Table 2 Clinical characteristics between groups with or without breastfeeding

\begin{tabular}{|c|c|c|c|c|c|}
\hline Parameters & $\mathbf{N}$ & Breast and mixed feeding $(n=97)$ & Artificial feeding $(n=58)$ & All $(n=155)$ & $\mathbf{P}$ \\
\hline Age, year & - & $28.66 \pm 3.22$ & $29.50 \pm 3.55$ & $28.97 \pm 3.36$ & 0.133 \\
\hline Educational level & & & & & 0.080 \\
\hline Junior and senior high & 31 & $14(45.16 \%)$ & $17(54.84 \%)$ & - & \\
\hline Undergraduate & 108 & $72(66.67 \%)$ & $36(33.33 \%)$ & - & \\
\hline Graduate and above & 16 & $11(68.75 \%)$ & $5(31.25 \%)$ & - & \\
\hline Work status & & & & & 0.987 \\
\hline Unemployed & 42 & $26(61.90 \%)$ & $16(38.10 \%)$ & - & \\
\hline Part-time or freelance & 14 & $9(64.29 \%)$ & 5 (35.71\%) & - & \\
\hline Full-time & 99 & $62(62.63 \%)$ & $37(37.37 \%)$ & - & \\
\hline Parity & - & $1.20 \pm 0.42$ & $1.45 \pm 0.50$ & $1.29 \pm 0.47$ & 0.001 \\
\hline Gestational weeks & - & $40.04 \pm 2.50$ & $39.72 \pm 2.24$ & $39.92 \pm 2.41$ & 0.429 \\
\hline Delivery method & & & & & 0.169 \\
\hline Vaginal & 114 & $75(65.79 \%)$ & $39(34.21 \%)$ & - & \\
\hline Cesarean section & 41 & $22(53.66 \%)$ & $19(46.34 \%)$ & - & \\
\hline Medication & & & & & 0.171 \\
\hline LDT & 131 & $79(60.31 \%)$ & $52(39.69 \%)$ & - & \\
\hline TDF & 24 & $18(75.00 \%)$ & $6(25.00 \%)$ & - & \\
\hline Gestational age at start of anti-viral therapy & - & $24.84 \pm 4.14$ & $24.67 \pm 2.96$ & $24.77 \pm 3.73$ & 0.794 \\
\hline Postpartum timing of stopping NAs treatment & & & & & 0.002 \\
\hline Delivery day & 110 & $78(70.91 \%)$ & $32(29.09 \%)$ & - & \\
\hline 1 month & 3 & $3(100.00 \%)$ & $0(0.00 \%)$ & - & \\
\hline 1.5 months & 18 & $8(44.44 \%)$ & $10(55.56 \%)$ & - & \\
\hline 2 months & 1 & $1(100.00 \%)$ & $0(0.00 \%)$ & - & \\
\hline 3 months & 1 & $1(100.00 \%)$ & $0(0.00 \%)$ & - & \\
\hline 6 months & 1 & $0(0.00 \%)$ & $1(100.00 \%)$ & - & \\
\hline 9 months & 1 & $0(0.00 \%)$ & $1(100.00 \%)$ & - & \\
\hline Never & 20 & $6(30.00 \%)$ & $14(70.00 \%)$ & - & \\
\hline Postpartum liver function & & & & & 0.132 \\
\hline Normal & 94 & $61(64.89 \%)$ & $33(35.11 \%)$ & - & \\
\hline Index rising & 23 & $11(47.83 \%)$ & $12(52.17 \%)$ & - & \\
\hline Postpartum viral load & & & & & 0.289 \\
\hline Normal & 54 & $37(68.52 \%)$ & $17(31.48 \%)$ & - & \\
\hline Abnormal & 79 & 47 (59.49\%) & $32(40.51 \%)$ & - & \\
\hline Infant gender & & & & & 0.261 \\
\hline Male & 78 & $52(66.67 \%)$ & $26(33.33 \%)$ & - & \\
\hline Female & 76 & $44(57.89 \%)$ & $32(42.11 \%)$ & - & \\
\hline Vaccination on time & & & & & 1.000 \\
\hline No & 1 & $1(100.00 \%)$ & $0(0.00 \%)$ & - & \\
\hline Yes & 154 & $96(62.34 \%)$ & $58(37.66 \%)$ & - & \\
\hline Successful hepatitis B vaccination & & & & & 0.145 \\
\hline No & 5 & $1(20.00 \%)$ & $4(80.00 \%)$ & - & \\
\hline Yes & 142 & $89(62.68 \%)$ & $53(37.32 \%)$ & - & \\
\hline Breastfeeding months & - & $7.92 \pm 4.47$ & - & $7.92 \pm 4.47$ & - \\
\hline Breastfeeding with wounds* & & & & & 0.768 \\
\hline
\end{tabular}


Table 2 Clinical characteristics between groups with or without breastfeeding (Continued)

\begin{tabular}{|c|c|c|c|c|c|}
\hline Parameters & $\mathbf{N}$ & Breast and mixed feeding $(n=97)$ & Artificial feeding $(n=58)$ & All $(n=155)$ & $\mathbf{P}$ \\
\hline No & 57 & $57(100.00 \%)$ & $0(0.00 \%)$ & - & \\
\hline Yes & 32 & $31(96.88 \%)$ & $1(3.13 \%)$ & - & \\
\hline Decision of feeding method & & & & & 0.363 \\
\hline Both parents & 85 & $56(65.88 \%)$ & $29(34.12 \%)$ & - & \\
\hline Physician & 39 & $25(64.10 \%)$ & $14(35.90 \%)$ & - & \\
\hline Mother alone & 31 & $16(51.61 \%)$ & $15(48.39 \%)$ & - & \\
\hline Infant birth body weight, $\mathrm{kg}$ & - & $4.15 \pm 1.57$ & $3.71 \pm 1.38$ & $3.99 \pm 1.51$ & 0.080 \\
\hline Infant birth body length, $\mathrm{cm}$ & - & $49.26 \pm 3.11$ & $49.40 \pm 2.09$ & $49.31 \pm 2.76$ & 0.760 \\
\hline Child with unusually healthy issue & & & & & 0.997 \\
\hline No & 143 & $90(62.94 \%)$ & $53(37.06 \%)$ & - & \\
\hline Yes & 4 & $2(50.00 \%)$ & $2(50.00 \%)$ & - & \\
\hline Knowledge of medication (LDT/TDF) & & & & & $<0.001$ \\
\hline No & 32 & $10(31.25 \%)$ & $22(68.75 \%)$ & - & \\
\hline Yes & 120 & $86(71.67 \%)$ & $34(28.33 \%)$ & - & \\
\hline Child with unusual height or weight & & & & & 0.651 \\
\hline No & 149 & $94(63.09 \%)$ & $55(36.91 \%)$ & - & \\
\hline Yes & 3 & $1(33.33 \%)$ & $2(66.67 \%)$ & - & \\
\hline
\end{tabular}

* "Breastfeeding with wounds" was defined as follows: 1) The mother's nipples were chapped or damaged, causing the baby to directly contact with the mother's blood during breastfeeding; or 2) The baby's lips and mouth may be damaged which can directly contact with breast milk

artificial feeding. This observation is inconsistent with the previous finding that multiparity children are more likely to be breastfed [35]. However, we did not survey the feeding habits of prior parity in those with multiple parities. Therefore, the clinical meaning of this phenomenon is limited.

Among the 110 cases of stopping NAs treatment at the delivery day in this study, 45.45 and $25.45 \%$ of cases adopted exclusive breastfeeding and mixed feeding, respectively; only $29.02 \%$ used artificial feeding. However, of the 20 continuing NAs treatment after delivery, $70.00 \%$ of the cases used artificial feeding. On the other hand, among the 120 cases with the knowledge of medication (LDT/TDF), $71.67 \%$ of cases adopted breastfeeding or mixed feeding, while $28.33 \%$ of cases used artificial feeding. By contrast, in 32 cases without the knowledge of medication, $68.75 \%$ of the cases used artificial feeding. In addition, multivariable logistic regression analysis confirmed that both postpartum timing of stopping NAs treatment and knowledge of medication were independent factors associated with noncompliance with breastfeeding recommendation.

The association between later postpartum timing of stopping NAs treatment and artificial feeding should be

Table 3 Associations between independent variables to groups with or without breastfeeding

\begin{tabular}{|c|c|c|c|c|}
\hline & Univariate & & Multivariable & \\
\hline Parameters & OR (95\%) & $P$ & OR (95\%) & $P$ \\
\hline Educational level & & 0.087 & & 0.177 \\
\hline Junior and senior high & ref. & - & ref. & - \\
\hline Undergraduate & 0.41 (0.18 to 0.93$)$ & 0.032 & $0.43(0.17$ to 1.10$)$ & 0.077 \\
\hline Graduate and above & 0.37 (0.10 to 1.34$)$ & 0.130 & 0.34 (0.07 to 1.65$)$ & 0.179 \\
\hline Parity & $3.12(1.54$ to 6.33$)$ & 0.002 & $3.21(1.42$ to 7.23$)$ & 0.005 \\
\hline Postpartum timing of stopping NAs treatment, levels & $1.30(1.13$ to 1.51$)$ & $<0.001$ & $1.36(1.15$ to 1.62$)$ & $<0.001$ \\
\hline Infant birth body weight, kg & 0.81 (0.64 to 1.03$)$ & 0.083 & $0.82(0.62$ to 1.09$)$ & 0.174 \\
\hline \multicolumn{5}{|l|}{ Knowledge of medication (LDT/TDF) } \\
\hline No & ref. & - & ref. & - \\
\hline yes & 0.18 (0.08 to 0.42$)$ & $<0.001$ & 0.22 (0.09 to 0.56$)$ & 0.001 \\
\hline
\end{tabular}


attributed to participants' concern that the drugs remaining in breastmilk may have an adverse effect on breastfed infants. However, the previous study shows that breastfed infants have a blood TDF concentration of only $2-4 \%$ of maternal blood [21], so breastfed infants have lower TDF exposure than those in exposed fetuses $[20,21]$. Recently, Hu et al. have compared the levels of TDF exposure in fetuses, breastfed infants, and children receiving tenofovir treatment. Their results reveal that the daily TDF dose ingested from breastmilk represented only $0.01-0.04 \%$ of the proposed pediatric therapeutic daily dose for children receiving TDF treatment and $0.5-16 \%$ of those exposed to the fetuses [22]. These findings suggest that TDF has low potential toxicity in breastmilk. It is worth mentioning that even healthcare workers may not have systematic and comprehensive knowledge about HBV MTCT [19]. Therefore, a health education leaflet that explains the low concentration of category B pregnancy medications LDT / TDF in breastmilk may help improve breastfeeding compliance of HBV-infected mothers receiving NAs treatment during pregnancy.

In the least Chinese guidelines for the prevention and control of mother-to-child transmission of hepatitis B virus (2019 edition) [36], breastfeeding is no longer prohibited for HBV-infected mothers receiving NAs treatment during pregnancy, but breastfeeding is still not clearly recommended. Our findings could provide a reference for revising the guidelines to recommend breastfeeding for HBV-infected mothers receiving pregnancy category B NAs treatment. However, since this was a retrospective, single-center study with relatively small sample size, evidence from a large prospective trial is required to recommend changes to the existing guidelines. In addition, we did not survey the feeding habits of prior parity in those with multiple parities. Moreover, we did not analyze health behaviors that are important confounding factors for breastfeeding willingness, such as maternal smoking and pre-pregnancy obesity. These limitations should be addressed in future studies.

\section{Conclusions}

In summary, our findings suggested that HBV-infected mothers who stopped NA treatment at late postpartum period or had or had less knowledge of medication were more likely to noncompliance with breastfeeding recommendation. Strengthening health education may improve breastfeeding compliance.

\section{Abbreviations}

HBV: Hepatitis B virus; WHO: World Health Organization; CHB: Chronic hepatitis B HCCs: hepatocellular carcinomas; MTCT: Mother-to-child transmission; HBIG: Hepatitis B immunoglobulin; TDF: Tenofovir disoproxil fumarate; LDT: Telbivudine; AASLD: American Association for the Study of Liver Diseases; SD: Standard deviation

\section{Supplementary Information}

The online version contains supplementary material available at https://doi. org/10.1186/s12884-021-04020-z.

Additional file 1. Questionnaire for postpartum Breastfeeding in hepatitis B virus-infected mothers taking LDT/TDF during pregnancy

\section{Acknowledgements}

The authors extend sincere appreciation to their patients who agreed to collaborate in this study, and Dr. Wei-Qiang Gan for his help in preparing the data of the manuscript.

\section{Authors' contributions}

EML and LXX carried out the study and drafted the manuscript. ZX and ZSM and JQL collected data and performed data analyses. CSL and YYM contributed to the study design, data analyses, and critical revision of the manuscript, as well as communication with the journal. All authors had access to the study data and reviewed and approved the final manuscript.

\section{Funding}

This study was funded by the National Key Research and Development Program of China (2017YFA0106300); Guangdong Province Xin-jiang Supporting Project (KTP20190272); and the Science and Technology Fund of Guangdong Province (2014A020212483).

\section{Availability of data and materials}

All data generated or analysed during this study are included in this published article and its supplementary information file.

\section{Declarations}

Ethics approval and consent to participate

This study was approved by the institutional review board of the Third Affiliated Hospital of Sun Yat-sen University. Written informed consent was obtained from each participant.

Consent for publication

Not Applicable.

\section{Competing interests}

The authors declare that they have no conflict of interest.

\section{Author details}

${ }^{1}$ Department of Infectious Diseases, the Third Affiliated Hospital of Sun Yat-Sen University, 600 Tianhe Road, Guangdong Province 510630 Guangzhou, China. ${ }^{2}$ Guangdong Provincial Key Laboratory of Malignant Tumor Epigenetics and Gene Regulation, Medical Research Center, Sun Yat-Sen Memorial Hospital, Sun Yat-Sen University, 510120 Guangzhou, China

Received: 28 December 2020 Accepted: 27 July 2021

Published online: 12 August 2021

\section{References}

1. Lavanchy D, Kane M. Global Epidemiology of Hepatitis B Virus Infection. In: Liaw YF, Zoulim F, editors. Hepatitis B Virus in Human Diseases. Swizerland: Springer International Publishing; 2016. p. 187-203.

2. WHO. Global hepatitis report, 2017. 2017. https://www.who.int/publications/ i/item/global-hepatitis-report-2017. Accessed 19 Apr 2017.

3. WHO. Global health sector strategy on viral hepatitis 2016-2021. World Health Organization. 2016. https://www.who.int/publications/i/item/WHOHIV-2016.06. Accessed 17 May 2016.

4. Lamberth JR, Reddy SC, Pan JJ, Dasher KJ. Chronic hepatitis B infection in pregnancy. World J Hepatol. 2015;7:1233-7.

5. No authors. Guidelines for the prevention, care and treatment of persons with chronic hepatitis B infection. Geneva: World Health Organization; 2015.

6. Ma L, Alla NR, Li X, Mynbaev OA, Shi Z. Mother-to-child transmission of HBV: Review of current clinical management and prevention strategies. Rev Med Virol. 2014;24:396-406 
7. Zhang H, Pan CQ, Pang Q, Tian R, Yan M, Liu X. Telbivudine or lamivudine use in late pregnancy safely reduces perinatal transmission of hepatitis $B$ virus in real-life practice. Hepatology. 2014;60:468-76.

8. Jackson V, Ferguson W, Kelleher TB, Lawless M, Eogan M, Nusgen U, et al. Lamivudine treatment and outcome in pregnant women with high hepatitis B viral loads. Eur J Clin Microbiol Infect Dis. 2015;34:619-23.

9. Pan CQ, Duan Z, Dai E, Zhang S, Han G, Wang Y, et al. Tenofovir to prevent hepatitis B transmission in mothers with high viral load. N Engl J Med. 2016; 374:2324-34.

10. Chen $\mathrm{HL}$, Lee $\mathrm{CN}$, Chang $\mathrm{CH}$, Ni YH, Shyu MK, Chen SM, et al. Efficacy of maternal tenofovir disoproxil fumarate in interrupting mother-to-infant transmission of hepatitis B virus. Hepatology. 2015;62:375-86.

11. Sarin SK, Kumar M, Lau GK, Abbas Z, Chan HLY, Chen CJ, et al. Asian-Pacific clinical practice guidelines on the management of hepatitis B: a 2015 update. Hepatol Int. 2016;10:1-98.

12. EASL. European Association for the Study of the Liver (EASL). 2017 Clinical Practice Guidelines on the management of hepatitis B virus infection. J Hepatol. 2017;67:370-98.

13. Sarri G, Westby M, Bermingham $\mathrm{S}$, Hill-Cawthorne $\mathrm{G}$, Thomas H. Diagnosis and management of chronic hepatitis B in children, young people, and adults: summary of NICE guidance. BMJ. 2013;346:13893.

14. Terrault NA, Chang KM, Hwang JP, Mm J, Brown RS. Update on Prevention, Diagnosis, and Treatment and of Chronic Hepatitis B: AASLD 2018 Hepatitis B Guidance Purpose and Scope of the Guidance HHS Public Access. Hepatology. 2018;67:1560-99.

15. Piratvisuth T, Han GR, Pol S, Dong Y, Trylesinski A. Comprehensive review of telbivudine in pregnant women with chronic hepatitis B. World J Hepatol. 2016:8:452-60

16. Victora CG, Bahl R, Barros AJD, França GVA, Horton S, Krasevec J, et al. Breastfeeding in the 21st century: Epidemiology, mechanisms, and lifelong effect. Lancet. 2016:387:475-90

17. World Health Organization. Consolidated guidelines on the use of antiretroviral drugs for treating and preventing HIV infection: recommendations for a public health approach. second. 2016. https://apps. who.int/iris/bitstream/handle/10665/208825/9789241549684_eng.pdf. Accessed 30 Apr 2020

18. Association HB of CM, Association IDB of CM. Guidelines for the Prevention and Treatment of Chronic Hepatitis B (2015 Update). Infect Dis Inf. 2015;28: 321-40.

19. Chen Y, Xie C, Zhang Y, Li Y, Ehrhardt S, Thio CL, et al. Knowledge regarding hepatitis $B$ mother-to-child transmission among healthcare workers in South China. J Viral Hepat. 2018;25:561-70.

20. Mirochnick M, Thomas T, Capparelli E, Zeh C, Holland D, Masaba R, et al. Antiretroviral concentrations in breast-feeding infants of mothers receiving highly active antiretroviral therapy. Antimicrob Agents Chemother. 2009;53: 1170-6.

21. Ehrhardt S, Xie C, Guo N, Nelson K, Thio CL. Breastfeeding while taking lamivudine or tenofovir disoproxil fumarate: A review of the evidence. Clin Infect Dis. 2015;60:275-8

22. Hu X, Wang L, Xu F. Guides concerning tenofovir exposure via breastfeeding: A comparison of drug dosages by developmental stage. Int J Infect Dis. 2019;87:8-12.

23. Xiao LX, Chen YR, Huang P, Mei YY, Pan CQ, Lin CS. The safety of antiviral therapy and drug withdrawal for the prevention of mother-to-child transmission of HBV during pregnancy. J Med Virol. 2020;92:3381-9.

24. Tran TT, Gordon SC, Fung S, Dinh P, Yee L, Martins EB, et al. Hepatitis B e antigen status and hepatitis B DNA levels in women of childbearing age with chronic hepatitis B infection screening for clinical trials. PLoS One. 2015;10:e0121632

25. Montoya-Ferrer A, Zorrilla AM, Viljoen J, Molès JP, Newell ML, Van de Perre $P$, et al. High level of HBV DNA virus in the breast milk seems not to contraindicate breastfeeding. Mediterr J Hematol Infect Dis. 2015;7: e2015042

26. Ying Jie Z, YiHan L, Qi Y, YuGang X, YueQin Z, QingQing Y, et al. Should chronic hepatitis B mothers breastfeed? A meta analysis. BMC Public Health. 2011;11:502

27. Association O. GB of CM. [Clinical guidelines for the prevention of motherto-child transmission of Hepatitis B virus]. Chinese J Obstet Gynecol. 2013; 48:151-4.

28. Chen S, Zhao Y, Liao X, Fu Y. [Effect of different feeding methods on mother-to-child transmission of HBV]. Nurs Pract Res. 2015;12:53-4.
29. (SMFM) S for M-FM. Dionne-Odom J, Tita ATN, Silverman NS. \#38. Hepatitis $B$ in pregnancy screening, treatment, and prevention of vertical transmission. Am J Obstet Gynecol. 2016;214:6-14.

30. European Association for the Study of the Liver. Electronic address: easloffice@easloffice.eu GM. European Association for the Study of the Liver U. Corpechot C, Invernizzi P, Jones D, Marzioni M, et al. EASL Clinical Practice Guidelines: The diagnosis and management of patients with primary biliary cholangitis. J Hepatol. 2017;67:145-72.

31. Benaboud S, Pruvost A, Coffie PA, Ekouévi DK, Urien S, Arrivé E, et al. Concentrations of tenofovir and emtricitabine in breast milk of HIV-1infected women in Abidjan, Côte d'Ivoire, in the ANRS 12109 TEmAA Study, step 2. Antimicrob Agents Chemother. 2011;55:1315-7.

32. Mirochnick M, Taha T, Kreitchmann R, Nielsen-Saines K, Kumwenda N, Joao E, et al. Pharmacokinetics and safety of tenofovir in hiv-infected women during labor and their infants during the first week of life. J Acquir Immune Defic Syndr. 2014;65:33-41.

33. Jourdain G, Ngo-Giang-Huong N, Harrison L, Decker L, Khamduang W, Tierney C, et al. Tenofovir versus Placebo to Prevent Perinatal Transmission of Hepatitis B. N Engl J Med. 2018;378:911-23.

34. Shang J, Wen Q, Wang CC, Liu K, Bai L, Tang H. Safety and efficacy of telbivudine for chronic hepatitis $B$ during the entire pregnancy: Long-term follow-up. J Viral Hepat. 2017:24:43-8.

35. Thapa S, Williamson N. Breast-feeding in Asia: An Overview. Asia-Pacific Popul J. 1990;5:7-24.

36. Association IDSB of CM. [Chinese Guideline for Prevention and Treatment of Hepatitis B Virus Mother-to-Child Transmission (2019 Edition)]. Chinese Infect Dis. 2019;37:388-96.

\section{Publisher's Note}

Springer Nature remains neutral with regard to jurisdictional claims in published maps and institutional affiliations.

\section{Ready to submit your research? Choose BMC and benefit from:}

- fast, convenient online submission

- thorough peer review by experienced researchers in your field

- rapid publication on acceptance

- support for research data, including large and complex data types

- gold Open Access which fosters wider collaboration and increased citations

- maximum visibility for your research: over $100 \mathrm{M}$ website views per year

At BMC, research is always in progress.

Learn more biomedcentral.com/submissions 